\title{
HYDROZOA E SCYPHOZOA EXISTENTES NO INSTITUTO PAULISTA DE OCEANOGRAFLA
}

I.

M. Vannucci

Com 4 estampas.

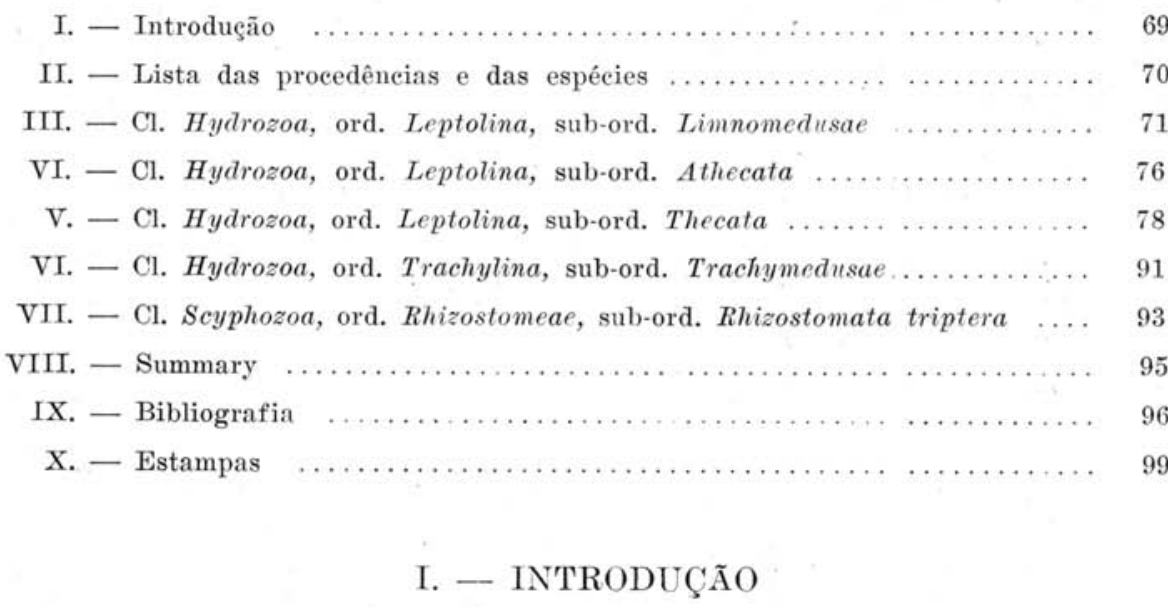

Esste trabalho foi iniciado, tendo-se como finalidade completar a lista dos Hydrozoa colecionados por W. Besnard durante a viagem à Ilha da Trindade, realizada em colaboração com a Marinha de Guerra Brasileira e efetuada de maio a julho de 1950. Aproveitei a ocasião para estudar outros espécimes que fazem parte da coleção do Instituto Paulista de Oceanografia, com o objetivo de continuar o inventário de nossa fauna de Celenterados.

Aproveito a oportunidade para agradecer ao prof. W. Besnard os exemplares que colecionou durante a mencionada viagem, bem como os provenientes da região de Cananéia. Agradeço também ao prof. E. Mareus e à Exma. Sra. Da. E. du Bois-Reymond Mareus os quais, em abril de 1949, também recolheram algumas colônias no canal de S. Sebastião, ao longo da costa da Ilha homônima, e que me foram entregues para determinação. Sou grata ao $\mathrm{Sr}$. João de Paiva Carvalho por ter posto à minha 
disposição, vários dados recolhidos nos seus longos anos de prática e pela revisão linguística do manuserito. Agradeço sinceramente à Srta. Carmen P. Arruda o auxílio prestado na confeeção dos desenhos.

Deixei de mencionar, neste trabalho, as espécies cuja ocorrência em determinado lugar não constitue novidade. As espécies, que constam da presente publicação, já figuram nas listas da resenha que efetuei sôbre a distribuição dos Hydrozoa nas costas do Brasil (Vannucei, constante dêste Boletim).

Ainda neste trabalho não elaborei chaves para a classificação dos Hydrozoa brasileiros, visto como está longe de se achar, não digo completo, mas nem mesmo adiantado o inventário das espécies dêsse grupo. Depreende-se êsse fato do grande número de espécies quer novas, quer ainda não registradas para as nossas águas, que são encontradas tôdas as vêzes que se efetuam coletas em lugares não anteriormente pesquisados e, mais ainda, em tôdas as ocasiões em que se realizam dragagens. Da enumeração presente, não menos de 10 espécies ou formas, i. é., quase $42 \%$ do total mencionado, eram desconhecidas na nossa fauna.

\section{II. -- LISTA DAS PROCEDENCIAS E DAS ESPÉCIES}

1). - Ilha da Trindade, entre 15 e $40 \mathrm{~m}$. de profundidade (maio-julho 1950) : Halocordyle fragilis, fértil ; Plumularia strobilophora, fértil ; Aglaophenia perforata.

2). - Banco de S. Tomé, entre $39-46 \mathrm{~m}$. de profundidade (maio-julho 1950) : Hebella scandens, epizóica sôbre Campanularia marginata; Syntecium tubithecum; Sertularia marginata f. laxa, fértil; Monotheca margaretta, f. typica; Aglaophenia perforata.

3). - 20 milhas ao largo de S. João da Barra, a $22 \mathrm{~m}$. de profundidade (maio-julho 1950) : Halocordyle fragilis, fértil; Dynamena quadridentata $f$. heterodonta, fértil; Sertularia perpusilla, fértil; Aglaophenia contorta.

4). - Cabo Frio, eêrea de $57 \mathrm{~m}$. de profundidade (maio-julho 1950): Halocordyle fragilis, fértil.

5). - Ilha de S. Sebastião, litoral Norte do Estado de S. Paulo: Olindias sambaquiensis; Obelia commissuralis, fértil (18-12-1950); Clytia elsae-oswaldae, fértil (abril de 1949); Dynamena cornicina; Sertularia erasmoi, fértil (abril de 1949); Sertularia marginata f. typica; Schizotricha diaphana, fértil (abril de 1949); Aglaophenia contorta; Aglaophenia late-carinata, fértil (abril de 1949).

6). - Baía de Santos e S. Vicente: Olindias sambaquiensis.

7). - Região de Cananéia: Olindias sambaquiensis; Liriope tetraphylla; ?Bougainvillia carolinensis; Calicella gabriellae, fértil (27-9-1949;)

Thaumantias raridentata; Lychnorhiza lucerna. 
1. - Olindias sambaquiensis, .......... p. 72, t. 1, Fig. 1, t. 2,

Fig. 4.

2. - Halocordyle fragilis sp. nov., ....... p. 76, t. 1, Fig. 2-3.

3. - ?Bougainvillia carolinensis, .......... p. 78.

4. - Calicella gabriellae sp. nov., ........ p. 79, t. 2, Fig. 5-7.

5. - Obelia commissuralis, ............ p. 80, t. 2, Fig. 8-9.

6. - Orthopyxis lennoxensis, ............. p. 81.

7. - Thaumantias raridentata, ........... p. 81, t. 2, Fig. 10.

8. - Clytia elsae-oswaldae, ............. p. 82.

9. - Campanularia marginata, .......... p. 82.

10. - Hebella scandens, ............... p. 82.

11. - Synthecium tubithecum, ............ p. 83.

12. - Dynamena quadridentata $f$. heterodonta, p. 83, t. 2, Fig. 11-12.

13. - Dynamena cornicina, ............. p. 84.

14. - Sertularia marginata f. typica, ........ p. 84.

15. - Sertularia marginata f. laxa, ......... p. 84 .

16. - Sertularia perpusilla, ............. p. 85, t. 2, Fig. 13-14.

17. - Plumularia lagenifera, ............ p. 86, t. 3, Fig. 15-16.

18. - Plumularia strobilophora, .......... p. 87, t. 3, Fig. 17-18.

19. - Schizotricha billardi, ............ p. 88, t. 3, Fig. 19-20.

20. - Monotheca margaretta f. typica, ...... p. 89.

21. - Aglaophenia perforata, ............ p. 89, t. 3, Fig. 21-23.

22. - Aglaophenia contorta, ............. p. 91.

23. - Liriope tetraphylla, ............. p. 91, t. 3, Fig. 24.

24. - Lychnorhiza lucerna, ............. p. 94, t. 4, Fig. 25-27.

\section{III. - Cl. HYDROZOA.}

Ord. LEPTOLINA. Sub-ord. LIMNOMEDUSAE Kramp 1938.

Fam. Olindiidae Haeckel 1879.

Limnomedusae com geração medusóide craspedota, tendo tôdas ou algumas das séries de tentáculos emergindo da superfície da ex-umbrela, todos ou parte dos tentáculos podendo apresentar discos adesivos. Ocorrem 4 ou 6 eanais radiais, nos quais se desenvolvem as gônadas. Pode haver divertículos centrípetos do canal radial, que terminam em fundo cego. Provàvelmente os litocistos têm origem endodérmica em todos os gêneros, podendo ser livres ou incluídos na mesogléa. A ocorrêneia de polipos acha-se presente em alguns gêneros, constituindo provàvelmente caráter de ordem geral para todos ou muitos dos representantes da família (Kramp 1938. 1939, p. 182; Vannucei 1948). 
Kramp (1938) evidenciou a necessidade de estabelecer uma nova sub-ordem entre os Hydrozoa, a das Limnomedusae, constituída pelas famílias Olindiidae, Moerisiidae e Williidae e que, juntamente com as sub-ordens Anthomedusae e Leptomedusae integram a ordem Leptolina. O mesmo autor mostrou haver vários indícios de terem as Limnomedusae uma posição filogenética primitiva. Pode-se acrescentar que a semelhança de alguns de seus representantes com espécies de outras sub-ordens dos Leptolina, e, por outro lado, também com certas Trachylina, reforȩa a opinião de se tratar de um grupo primitivo, se bem que especializado, sob muitos pontos de vista.

\section{1. - Olindias sambaquiensis Fr. Müller 1861.}

t. 1, Fig. 1, t. 2, Fig. 4 .

Olindias sambaquiensis Fr. Müller 1861, p. 16, t. 9.

Olindias sambaquiensis Maas 1905, p. 48.

Olindias sambaquiensis Bigelow 1909, p. 109.

Olindias sambaquiensis Mayer 1910, p. 354.

Os adultos alcançam até $10 \mathrm{~cm}$. de diâmetro, podenđo apresentar esboços de gônadas já quando têm sòmente $4 \mathrm{~cm}$. de diâmetro. A umbrela tem encurvamento inferior ao de um hemisfério, alcançando $30 \mathrm{~mm}$. de altura nos indivíduos maiores. Existem 4 canais radiais completos, euja côr vai do rosa ao vermelho vivo, e que abrangem tôda a extensão existente entre o estômago quadriangulado e o canal circular. Tanto os canais radiais como o circular são muito delgados, transparentes, quando o animal está em jejum, branco leitoso depois dêle se ter alimentado. Do canal circular saem canais centrípetos em fundo cego, transparentes no animal vivo, com comprimento variável, tanto mais longos quanto mais antigos e cujo número aumenta com o erescimento da medusa. Pode haver 27 dêstes em cada quadrante, sendo de 17-18 numa medusa de $35 \mathrm{~mm}$. de diâmetro. O manúbrio é quadriangulado, com margem labial sinuosa e de côr amarela viva. O manúbrio é fortemente contrátil, tendo, em contração média, pouco mais da metade do comprimento do raio da umbrela. Os tentáculos pertencem a três séries diferentes. Os primários, que fazem parte da primeira série, são ôcos, vermelho grenat, emergem da ex-umbrela em alturas diferentes acima da margem, são providos de anéis de enidocistos, que podem ser completos ou dotados de pequenas falhas irregulares. No ápice há um botão de enidocistos, quase esférico. Dêstes tentáculos podem existir até 25 em cada quadrante, havendo cêrea de 15-17 em indivíduos de $35 \mathrm{~mm}$. de diâmetro; são caracterizados como "rigidos" por Mayer (1910, p. 354), mas o termo está mal escolhido, pois apesar de serem menos contráteis e elásticos do que os demais, êles não são pròpriamente nem rígidos nem imóveis. A segunda série de tentáculos, a dos secundá. 
rios, é representada por filamentos longos, muito finos e flexíveis, ôcos, amarelo vivo, que emergem da margem umbrelar; a parte velar, proximal, dêstes tentáculos é desprovida de nematocistos, havendo nesta região uma faixa fortemente muscular, formada sobretudo por fibras longitudinais. A face umbrelar é provida de enidocistos abundantes, dispostos em semicíreulos. A parte distal dêsses tentáculos tem alternadamente semi-anéis de cnidocistos na face velar e na face umbrelar; no ápice do tentáculo há um pequeno botão de enidocistos. Êstes tentáculos da segunda série podem atingir a 62-75 por quadrante em indivíduos completamente crescidos e são em número de $35-45$ nos espécimes de $35 \mathrm{~mm}$. de diâmetro. Êstes tentáculos têm o comprimento de 4 a 6 vêzes o diâmetro da umbrela. A terceira série de apêndices é representada por protuberâncias claviformes, cujo número aumenta sensivelmente com o crescimento da medusa ("clubshaped" appendages de Mayer). O seu número varia de 22 a 25 em medusas de $35 \mathrm{~mm}$. de diâmetro até atingirem a $50 \mathrm{em}$ indivíduos completamente desenvolvidos. Ocorre um par de litocistos ladeando a base de cada tentáculo primário.

As gônadas são dobras fortemente pregueadas, abrangendo tôda a extensão dos canais radiais em medusas grandes, e deixando livre a parte central dos canais radiais em medusas menores. O seu desenvolvimento dá-se gradualmente, do canal circular para o centro. As côres do animal são muito vivas, predominando o amarelo e o vermelho, êste último no sistema gastro-vascular, o primeiro, sobretudo nos tentáculos marginais.

Procedência. - Baía de Santos, S. Vicente (perto de Santos), Cananéia, Canal de S. Sebastião.

Distribuição. - De Sta. Catarina à Ilha de S. Sebastião.

Discussão. - Mayer (1910, p. 354) admite a possibilidade de O. tenuis Browne ser apenas uma variedade menor de 0 . sambaquiensis. Julgo, porém, que as duas espécies, cuja área de distribuição conhecida é separada por largo intervalo, não devem ser consideradas sinônimas, e também $\boldsymbol{O}$. tenuis não pode ser considerada apenas uma variedade nórdica menor da forma typica. Os caractéres distintivos, que julgo suficientes, são: $1^{\circ}{ }^{\circ}$ A estrutura diferente dos tentáculos de $O$. tenuis, que são providos de discos adesivos dos quais não encontro traços em $O$. sambaquiensis; $\left.2 .^{\circ}\right)$ O número de tentáculos, canais centrípetos e litocistos de indivíduos de $35 \mathrm{~mm}$. de diâmetro de $O$. sambaquiensis (valores indicados acima), diferem das indicações de Mayer (1. c.) para O. tenuis, cujo diâmetro máximo indicado é de $35 \mathrm{~mm}$; $3^{\circ}{ }^{\circ}$ ) Umbrela hemisférica em o. tenuis e mais baixa do que um hemisfério em 0 . sambaquiensis.

Notas biológicas. - Mayer (1. e.) afirma ser Fr. Müller o único naturalista que viu a medusa viva. Esta afirmação poderia dar a impressão errônea de se tratar de uma espécie rara. Esta medusa ocorre durante o ano todo, sendo porém muito mais abundante nos meses de inverno, (também Müller 1861, p. 312), época em que áparecem verdadeiros cardu- 
mes tanto em baías costeiras, como no mar aberto, não longe da costa. É até considerada como praga pelos pescadores, cujas malhas de rêdes, por vêzes, chega a obstruir parcialmente com sua gelatina. Como pude depreender de protocolos inéditos do Sr. João de Paiva Carvalho, efetuados durante o ano de 1942, entre abril e outubro inclusive, nos arredores de Santos, estas medusas ocorrem com mais freqüência de julho a outubro, sendo encontradas até a 4 milhas da costa, em temperatura de água que oscilou de $21^{\circ} \mathrm{C}$. a $22^{\circ} \mathrm{C}$. na superfície. Nesta ocasião, foram pescadas também com rêde de arrasto. Ao que parece, a grande freqüência do medusas causa o afastamento de camarões para regiões mais distantes da costa.

Os representantes desta espécie são fàcilmente mantidos vivos em aquários, mesmo improvisados, servindo para êste fim qualquer recipiente de vidro com bôca larga e fundo recoberto por areia ou pedregulho. A ventilação por meio de uma bomba de ar é recomendável, mas não indispensável para se manter os animais vivos durante muitos dias; é necessário que se promova a substituição diária das perdas por evaporação com água nova, pois êsses animais eurialinos suportam mais fàcilmente a diminuição do que o aumento da salinidade. Consegue-se alimentar fàcilmente os animais administrando-lhes, aos pedaços, fragmentos de tatusinho (Crustacea Isopoda, Armadillidium sp.,); ou porções de carne de guarú (Phalloptycus caudimaculatus) ou outros peixes pequenos; é necessário retirar imediatamente os restos de alimento deixado pelas medusas, a fim de que não apodreçam e dêste modo poluam a água. Os animais famintos conservam os tentáculos contraídos, apresentando-se os marginais pouco mais compridos do que os ex-umbrelares; êstes indivíduos pulsam contìnuamente e nadam quase sem parar. Ao ser jogado o alimento no aquário, desde logo os tentáculos marginais se estendem, à procura do mesmo, a umbrela se agacha no fundo, o manúbrio move-se contìnuamente em tôdas as direções, em busea da prêsa. Sôbre o fundo do aquário as medusas podem deslocar-se, por meio de movimentos lentos (searching reaction), sem efetuar contrações bruscas da umbrela, que representam o seu modo habitual de locomoção. Quando os tentáculos encontram o fragmento, envolvem-no, e passam a contrair-se em direção ao manúbrio, que, por sua vez, se distende em direção ao alimento até alcançá-lo. Nessa fase, o contôrno da umbrela deforma-se ativamente, sendo sua forma muito variável e diferente de circular. Em temperatura ambiente de $22^{\circ} \mathrm{C}$, todo êsse processo se realiza em 4-5 minutos, num aquário pequeno, desde que o percurso rumo à prêsa não seja muito longo. Dentro de meia hora, esta, mesmo sendo grande, estará inteiramente alojada no estômago. Se, porventura, outros tentáculos de um indivíduo farto encontrarem um segundo fragmento de alimento, êles o envolvem e podem arrastá-lo por certo tempo, mas o manúbrio não toma conhecimento do fato e, por via de regra, o segundo fragmento é abandonado. Pela rapidez com que as medusas reagem ante qualquer partícula alimentícia introduzida no aquário, sobretudo quando a prêsa está ferida e há escoamento de sucos, torna-se evidente que êstes animais possuem órgãos quimo-receptores muito eficientes. É muito possí- 
vel que êstes sejam os tentáculos de terceiro tipo, mas, para esclarecer definitivamente êste ponto, são necessárias pesquisas experimentais e histológicas, que talvez possam em breve ser tentadas.

Depois de fartas, as medusas ficam no fundo, com a umbrela e todos os tentáculos estendidos ao máximo. Alguns dos tentáculos ex-umbrelares são mantidos verticalmente para cima, outros horizontalmente. Os tentáculos marginais efetuam movimentos lentos e contínuos, às vêzes deslocando as partículas de areia sôbre a qual se encontram; de vez em quando alguns se contraem em espiral. O manúbrio também realiza movimentos lentos e contínuos em tôdas as direções.

$\mathrm{Na}$ temperatura ambiente de $23^{\circ} \mathrm{C}$, em intervalos de aproximadamente 1 a 1 minuto e meio, a umbrela realiza uma ou duas contrações bruscas, sem que se dê um deslocamento sensível do animal. Em cada 4' ou 5' o animal passa a efetuar movimentos natatórios, contraindo-se durante cêrca de 1', após o que, lentamente deixa-se cair sôbre o fundo. E provável que as contrações sem finalidade natatória, realizadas também pelo animal farto, sejam movimentos respiratórios, pois êles se produzem em intervalos maiores em aquários arejados pela bomba de ar. Em todos os casos observados, os resíduos quitinosos ou ósseos da prêsa já tinham sido rejeitados 24 horas depois da ingestão e o estômago parecia vazio, exibindo côr leitosa, o mesmo acontecendo com os canais radiais que eram transparentes no animal faminto. Encontrei, em estado natural, como já anteriormente também Fr. Müller (1861, p. 317), algumas medusas com o estômago preenchido por um pequeno alevino, e notei que as medusas se acumulam nos pequenos remansos onde ocorrem cardumes de alevinos os quais são eaçados ativamente. No mar livre, as contrações umbrelares das medusas são muito mais espaçadas do que nos aquários, confirmando a hipótese de terem elas caráter respiratório, pois evidentemente o mar deve estar mais ventilado, pelo menos nas regiões por elas freqüentadas, do que um aquário sem ventilação especial, cuja temperatura, em S. Paulo, no verão, é sempre superior aos $20^{\circ} \mathrm{C}$. e por vêzes ultrapassa os $25^{\circ} \mathrm{C}$.

Nadando, as medusas progridem normalmente com o polo aboral voltado para a frente, mas são capazes também de efetuar algumas contrações sucessivas com o manúbrio dirigido para cima. Como é sabido, também em relação a numerosas outras medusas, sobretudo entre as Limnomedusae, às vêzes pousam sôbre o fundo com a ex-umbrela para baixo.

O homem é sensível à ação dos enidocistos, especialmente as erianças ou as regiões do corpo onde a pele se apresenta mais delicada. Para que essa sensação seja perceptível, é necessário que os tentáculos permaneçam em contacto com a pele durante um determinado tempo; a sua ação sôbre a conjuntiva, porém, é muito rápida e intensa e de efeito mais duradouro,. bastando para irritá-la, esfregar os olhos depois de se ter pegado no animal (informação verbal do Sr. João de Paiva Carvalho). 
IV. - Cl. HYDROZOA.

Ord. LEPTOLINA. Sub-ord. ATHECATA (ANTHOMEDUSAE).

Família Halocordylidae Stechow 1922.

Hidróides atecados caracterisados por apresentarem tentáculos orais capitados dispostos em um ou mais verticilos e tentáculos aborais filiformes. Algumas Eleutheriinae também apresentam êsses dois tipos de tentáculos, mas nesse caso, essas espécies não exibem esqueleto erecto bem desenvolvido.

2. - Halocordyle fragilis sp. nov.

t. 1, Fig. 2-3.

Halocordyle sp. Vannueci 1950, p. 83, t. 1, f. 1.

As colônias, ramificadas, são grandes, alcançando até $30 \mathrm{~cm}$. de altura. Apresentam perisarco preto, grosso, rígido, não obstante, são frágeis como vidro. Os internódios caulinares são longos, determinando grande afastamento dos hidrocládios, dispostos alternadamente e também muito frágeis. Os hidrocládios não têm a disposição penada típica das demais espécies do gênero, sendo em geral dispostos em planos diferentes, com uma forte tendência para uma disposição espiral regular. Os pedúnculos dos hidrantes não são dispostos todos do mesmo lado do cládio, mas sim alternadamente à direita e à esquerda do mesmo, podendo haver até 45-50 num único hidrocládio. O caule e os cládios são anelados acima das ramificações e acima da inserção dos pedúnculos dos hidrantes sempre há 5-9 anelações. Os pedúnculos apresentam 2-3 $\mathrm{mm}$. de comprimento, têm 7-10 anelações na base e 1 ou 2 grupos de anelações na porção intermediária. O perisarco dos pedúnculos torna-se gradualmente mais fino e mais claro da base para o ápice. Os hidrantes têm pedúnculo muito fino, e corpo alongado, com base larga. O hipostoma apresenta-se ora curto e largo, com orifício oral amplamente aberto, ora longo e delgado, com ápice cônico e bôca fechada. Existem cêrca de 14 tentáculos aborais, filiformes, cujo ápice ultrapassa a bôca. Ocorrem também 12 tentáculos curtos, capitados, dispostos em 3 verticilos, sendo que os do verticilo superior ultrapassam de pouco o nível da bôca; os tentáculos capitados do mesmo verticilo não se dispõem rigorosamente no mesmo plano, podendo estar deslocados para cima ou para baixo do mesmo. Entre os tentáculos capitados e os filiformes ocorrem os gonóforos.

\section{Medidas. -}

Distância entre hidrocládios sucessivos ...... $5-10 \mathrm{~mm}$.

Distância entre pedúnculos tecais sucessivos ... 1,9-2,1 mm.

Espessura do hidrocaule $\ldots \ldots \ldots \ldots \ldots \ldots \ldots$ 0,4-1,0 mm.

Espessura dos hidrocládios . . . . . . . . . . 200-300 micra. 
Procedência. - Ilha da Trindade, S. João da Barra, Cabo Frio. Fértil em maio-julho 1950. Até $57 \mathrm{~m}$. de profundidade.

Discussão. - A evolução das espécies do gênero Halocordyle deu-se, provàvelmente, ao longo de uma linha que vai das espécies mais primitivas, com tentáculos orais dispostos irregularmente, passando por espécies com uma parte dos tentáculos dispostos em verticilo, até as espécies mais evoluidas, em que todos os tentáculos são dispostos em verticilos. $H$. fragilis é, portanto, uma espécie das mais evoluidas do gênero, tendo além disso, perdido a distribuição regular dos hidrocládios. A escassa densidade de polipos pode ser devida a uma influência direta da profundidade sôbre o hábito da colônia. Conhecem-se outros casos semelhantes, por exemplo Bougainvillia ramosa que, em certa profundidade, apresenta caules e ramos mais finos, dando-se o mesmo com outras espécies, ao ponto de terem sido consideradas espécies diferentes colónias distintas da mesma e que apresentavam hábito grandemente alterado pelas condições físicas do meio ambiente. A espécie presente distingue-se desde logo das demais do gênero pelo hábito geral peculiar à colônia. $\mathrm{O}$ conjunto não tem o aspecto de pena, característico das demais espécies, mas sim o de um longo arame ramificado irregularmente e com hidrocládios distribuidos esparsamente ao longo do eaule. Em resumo, o que mais chama a atenção é a pequena densidade de polipos. Não julgo conveniente estabelecer um novo gênero, baseando-me nesses caractéres, pois estas particularidades, se bem que tenham efeito marcante sôbre a fisionomia da colónia, não atingem nenhum caráter essencial, visto como os polipos e os gonóforos são totalmente iguais aos típicos dêste gênero. São ainda características distintivas desta espécie: sua grande fragilidade (o caule e os cládios quebram-se ao serem apenas tocados, deixando escapar um ruido semelhante ao de palha sêca), suas medidas, a disposição dos hidrantes, a distribuição das anelações do perisarco e, por fim, o número e distribuição dos tentáculos. Os pedúnculos tecais, os hidrantes e os gonóforos são tìpicamente os do gênero Halocordyle (Pennaria). Stechow (1922, p. 144; 1923, p. 47) mostrou que o nome Pennaria Oken não pode ser mantido, devendo ser substituido por Halocordyle Allman 1872, o primeiro nome válido atribuido a uma espécie dêste gênero. Não obstante, o nome Pennaria é muito conhecido e será difícil a sua substituição, pois, em alguns lugares, figura até na nomenclatura popular, como por exemplo em Nápoles, em relação a Halocordyle disticha (= Pennaria cavolinii) e em Woods Hole, quanto a Halocordyle tiarella (= Pennaria tiarella).

Família Oceanidae Vanhöffen 1891.

Anthomedusae com 4 ou 8 gônadas localizadas nos interradii ou adradii do estômago. Os tentáculos marginais quer sejam isolados ou reunidos em leque, não são nem penados nem ramificados. 
Sub-família Margelinae Haeckel 1879.

Oceanidae com tentáculos orais e 4 canais radiais simples.

\section{3. - ?Bougainvillia carolinensis (McCrady) 1857 .}

Bougainvillia carolinensis Mayer 1910, p. 165, t. 16, f. 7, 9; t. 17, f. 7 .

Possúo alguns exemplares de medusas jovens que muito provàvelmente pertencem a essa espécie. A umbrela, espessa, alta, alcança nos maiores exemplares que tenho em mãos, $1 \mathrm{~mm}$. de altura, e não mais de 800 micra de diâmetro máximo (material montado em bálsamo). Os 4 bulbos marginais, esféricos e pequenos, apresentam eada um, primórdios de 6 tentáculos dispostos em leque e 6 ocelos pretos na base de cada tentáculo. Existem 4 canais radiais, o estômago é grande, o pedúnculo oral curto, os primórdios de gônadas, presentes em alguns indivíduos, estão em posição interradial; os 4 tentáculos bucais são ramificados duas vêzes dieotomicamente, aparentemente já atingiram completo desenvolvimento quanto ao número de ramificações e são capitados.

Apesar de existirem primórdios de gônadas, parece-me que êstes exemplares são ainda imaturos não sendo possível afirmar seguramente sua classificação específica.

Procedência. - Cananéia, 24-6-49, entre a Ponta e a Ilha do Cambriú. Material colecionado por W. Besnard, com rêde pelágica, às 12 horas, com maré montante, temperatura da água de $21^{\circ}, 7 \mathrm{C}$.

Distribuição. - Do Cabo Cod (Massachussets) às Ilhas Tortugas, no mar dos Caraibas.

$$
\text { V. - Cl. HYDROZOA. }
$$

Ord. LEPTOLINA. Sub-ord. THECATA (LEPTOMEDUSAE).

\section{Família Campanulinidae.}

Hydroida tecáforos, com hidrotecas pedunculadas, cilíndricas, providas de opérculo formado por numerosas valvas, hidrante com hipostoma cônico.

\section{Sub-família Calicellinae.}

Campanulinidae com opéreulo formado por valvas livres ou festonadas, e margem nitidamente demareada da teca; gonotecas providas de . conformação definida. 


\section{4. - Calicella gabriellae sp. nov.}

t. 2, Fig. 5-7.

Trofosoma. - Uma colônia extensa foi encontrada sôbre uma concha vasia de biválvo, constituida por caules de até $7 \mathrm{~cm}$. de comprimento. Os caules são moles e flexíveis, formados por artículos tecados, havendo às vêzes um artículo intermediário atecado. Os artículos tecados apresentam uma forte curvatura. As tecas são eilíndricas, com base afunilada, com ampla eâmara basilar e diafragma distinto. O pedúnculo tem comprimento variável, de acôrdo com o número de anéis de que é constituido, podendo variar de 3 a 7 anéis. As peças operculares são de formato triangular, longas, em número de 10 a 12 ; estão articuladas na margem tecal que é ondulada e provida de leve refôrȩo anelar.

Gonosoma. - Os gonângios formam-se na axila dos pedúnculos das tecas; são cônicos, com base arredondada e pedúnculo sempre muito curto, formado por poueos anéis. A parte distal das gonotecas apresenta uma pequena saliência digitiforme, muito earacterística. Os gonângios são notáveis pelo seu tamanho diminuto. O cenosarco contém um esporosaco, com poucos óvulos já crescidos no material que foi colecionado no mês de setembro.

\section{Medidas. -}

Profundidade das tecas, excluindo o opérculo ... 680-815 micra

Comprimento das valvas operculares ........ 270-305 "

Comprimento dos pedúnculos . ........... 400-800 "

Profundidade das gonotecas . . . . . . . . . . 880-920 "

Diâmetro máximo das gonotecas ........... 760-790 "

Procedência. - Região de Cananéia, 27-9-49, canal, diante do Perequê; material colecionado por W. Besnard.

Discussão. - Esta espécie distingue-se fàcilmente das demais do gênero, sobretudo de C. syringa, vastamente distribuida, que não forma caules erectos, brotando todos os pedúnculos tecais sôbre os estolões basilares; além disso as tecas dessa espécie não apresentam diafragma. De C. fastigiata (Alder), entre outros caractéres, difere pelas medidas. Morfològicamente, C. gabriellae lembra Lovenella clausa (Loven 1835), da qual difere, essencialmente, pelo caráter que separa os dois gêneros, a saber: produção de medusas livres em Lovenella e ocorrência de esporosacos, em Calicella. Afora êste fato fundamental, a presente espécie distingue-se de $L$. clausa pela forma e tamanho das gonotecas e pela altura do opéreulo. 
Família Campanulariidae.

\section{5. - Obelia commissuralis Mc Crady 1859.}

t. 2, Fig. 8-9.

$\begin{array}{ccc}\text { Obelia commissuralis } & \text { Allman } 1864, \text { p. } 372 . \\ " & " & \text { Torrey } 1902, \text { p. } 56 . \\ " & " & \text { Mayer } 1910, \text { v. } 2, \text { p. } 244 \text {, f. } 124 . \\ " & " & \text { Nutting } 1915, \text { p. } 83, \text { t. } 21, \text { f. } 1-5 . \\ " & " & \text { Bedot } 1925, \text { p. } 300 .\end{array}$

Trofosoma. - Encontrei uma extensa colônia desta espécie recobrindo um pedaço de bambú já semi-apodrecido, flutuando livremente no mar, do comprimento de cêrea de $40 \mathrm{~cm}$. A colônia de Obelia recobria tôda a face submersa com um número enorme de caules densamente aproximados uns dos outros. Os cáules alcançam até $38-40 \mathrm{~mm}$. de comprimento, são ramificados, finos e muito flexíveis. Por via de regra os internódios basais são desprovidos quer de técas, quer de ramos; isto se dá provàvelmente devido à grande densidade dos caules, pois a parte periférica da colônia apresenta cáules em que as técas se acham presentes desde a sua parte inferior. Os internódios caulinares possuem 3-6 anelações logo acima dos enós. Os pedúnculos tecais inserem-se na parte distal de cada internódio. Freqüentemente forma-se, na base de um pedúnculo tecal, um segundo pedúnculo mais curto. As ramificações surgem irregularmente, quer no processo distal dos internódios caulinares, quer na axila dos pedúnculos ou até podem formar-se duas no mesmo internódio eaulinar. Os pedúnculos das tecas são inteiramente anelados, mas seu comprimento muito irregular, varia desde o de poucos anéis até quase $1 \mathrm{~mm}$. apresentando, nestes casos, a poręão intermediária lisa. As técas são cônicas, com margem lisa, o diafragma delimita uma nítida câmara basilar, e a sua parede é muito fina. Os polipos apresentam até 24-30 tentáculos, o hipostoma é representado por um cône muito alongado, separado da corôa de tentáculos por uma constrição anelar profunda.

Gonosoma. - Os gonângios formam-se em qualquer lugar dos cáules, nos processoś caulinares, na axila de pedúnculos tecais ou de ramificações primárias ou secundárias ou nos próprios ramos. O pedúnculo eurto, é formado por 5-7 anelações. As gonotécas são fusiformes ou têm forma de cône muito alongado. Existe um colarinho ao redor do orifício. No mesmo blastóstilo pode haver até 26 brotos de medusas em vários estádios de desenvolvimento. Geralmente há cêrca de 18. Encontrei poucos gonângios vazios, alguns em vias de esvaziamento; a maioria, porém, estava ainda intacta havendo poucos blastóstilos em crescimento. Ao se desprenderem, as medusas têm 16 tentáculos e não apresentam nem vestígios de gônadas; pertencem à espécie descrita sob o mesmo nome. 


\section{Medidas. -}

Comprimento dos internódios caulinares ...... 720-960 micra

Diâmetro do caule ao nível das articulações .... 95-140 "

Comprimento do pedúnculo das técas ....... 150-800 "

Profundidade das técas, inclusive a câmara basal 335-525 "

Diâmetro do orifício das técas ............ 235-400 "

Profundidade dos gonângios ............. 950-1460 "

Diâmetro máximo dos gonângios ........... 280-375 "

Procedência. - Canal de S. Sebastião, litoral Norte do E. de S. Paulo, fértil em 18-12-1950.

Distribuição. - Costa Atlântica dos Estados-Unidos, de Charleston Harbor para o Norte; S. Francisco, Califórnia. Até $18 \mathrm{~m}$. de profundidade.

\section{6. — Orthopyxis lennoxensis (Jäder.) 1903.}

Orthopyxis lennoxensis Vannucei Mendes 1946, p. 544, t. 1, f. 3-5:

Procedência. - Ilha de S. Sebastião, canal, fértil em abril de 1949, gonângios femininos; uma colônia extensa, novamente encontrada sôbre feofíceas.

7. - Thaumantias raridentata (Alder) 1862.

t. 2, Fig. 10 .

Campanularia raridentata Billard 1906, p. 173.

\begin{tabular}{|c|c|c|}
\hline ?Campanularia & $"$ & Fraser 1912 , p. 357, f. 14 . \\
\hline$"$ & " & Issel 1912, p. 392. \\
\hline$"$ & " & Stechow 1919 , p. 58, f. Q. \\
\hline Thaumantias & $"$ & 1923 , p. 107 , f. M. \\
\hline Campanularia & $"$ & Bedot 1925 , p. 126. \\
\hline$"$ & $"$ & Cunha 1940, p. 117. \\
\hline$"$ & $"$ & Cunha 1944 , p. 59. \\
\hline
\end{tabular}

Trofosoma. - Encontrei sòmente uma colônia jovem desta espécie, ainda formada por uma única téca. Esta é profunda, a parte distal é cilíndrica, a basal é cônica, a câmara basal é muito ampla e delimitada por um septo bem desenvolvido. A margem tecal é provida de 8 dentes profundos com ápice embotado e reentrâncias arredondadas entre êles. O pedúnculo desta téca apresenta cinco anelações estreitas na base e quatro na sua parte distal. A porção intermediária do pedúnculo não tem anelações distintas, apresentando porém, contôrno ondulado. O perisarco é muito fino e delicado. Esta téca é epizóica sôbre Calicella gabriellae. 


\section{Medidas. -}

Profundidade da téca $\ldots \ldots \ldots \ldots \ldots \ldots \ldots \ldots, 400$ micra

Diâmetro do orifício da téca .............. 144 micra

Procedência. - Região de Cananéia, canal diante do Perequê. Colecionada em setembro de 1949.

Distribuição. - Helgoland; Ilha de Man; Golfo da Gasconha ; Marrocos; Açores; Mediterrâneo; Ilha de S. Tomé (Indias ocidentais).

Discussão. - Esta espécie foi descrita e ainda é comumente conhecida sob o nome de Campanularia raridentata. Stechow (1923, p. 108) deslocou-a para o gênero Thaumantias, de acôrdo com os critérios por êle adotados ao elaborar o quadro sistemático dos gêneros das Campanulariidae e publicado no trabalho citado. Tal deslocamento é a meu ver, sòmente aceitável a título de hipótese, visto como, para tanto, seria necessário saber se a espécie se reproduz por medusas ou esporosacos. Stechow ao transferir a espécie para o gênero Thaumantias baseou-se ùnicamente nos caractéres do diafragma.

\section{8. - Clytia elsae-oswaldae Stechow 1914.}

Clytia elsae-oswaldae Vannucei Mendes 1946, p. 550, t. 2, f. 12-13; 19.

Procedência. - Exemplares típicos foram coletados em mar raso, na Ilha de S. Sebastião, canal; fértil em abril de 1949.

\section{9. - Campanularia marginata (Allman) 1888.}

Campanularia marginata Vannueci 1949 , p. 228, t. 1, f. 7-10.

$$
\text { " } \quad \text { Vannucei 1950, p. } 84 .
$$

Procedência. - Banco $\mathrm{S}$. Tomé, entre 39 e $46 \mathrm{~m}$. de profundidade.

Distribuição. - Trindade, Banco Jaseur, a $20^{\circ} 33^{\prime}$ lat. S. e $40^{\circ} 14^{\prime}$ long. W. Sempre encontrada a certa profundidade e novamente servindo de substrato a Hebella scandens.

Família Lafoeidae.

10. - Hebella scandens (Bale) 1888.

Hebella scandens Bedot 1925, p. 226.

" $\quad$ Vannucei 1949, p. 236, t. 2, f. 22-23. 
Procedência. - Encontrei, novamente, esta espécie epibiótica sôbre Campanularia marginata. Banco S. Tomé, entre 39 e $46 \mathrm{~m}$. de profundidade.

\section{Família Synthecidae.}

\section{1. - Synthecium tubithecum (Allman) 1877.}

Synthecium tubithecum Bedot 1918, p. 269.

$$
\begin{array}{lll}
" & " & \text { Bedot } 1925, \text { p. } 431 . \\
" & \quad & \text { Vannueci } 1950, \text { p. } 86, \text { t. } 1, \text { f. } 4 .
\end{array}
$$

Procedência. - Banco S. Tomé, entre 39 e $46 \mathrm{~m}$. de profundidade.

\section{Família Sertularidae.}

12. - Dynamena quadridentata (Ell. \& Sol. 1786)

f. heterodonta (Jarvis) 1922.

$$
\text { t. 2, Fig. 11-12. }
$$

Sertularia gracilis Billard 1905, p. 334.

Pasythea heterodonta Jarvis 1921, p. 344, t. 24, f. 11-12.

Dynamena heterodonta Billard 1925, p. 198, f. 44.

Trofosoma. - As colônias presentes crescem sôbre feofíceas, os estolões apresentam espessamentos perisarcais internos. Os cáules são muito curtos com poucos pares de técas. Na maioria dos casos, os pares de técas aparecem isolados, mas, por vêzes, são reunidos em grupos de dois pares. Ocorrem dois dentes laterais na margem tecal e um pequeno mediano adeaulinar.

Gonosoma. - Os gonângios são alongados, com 5-6 reintrâncias anelares profundas. $O$ orifício é amplo, eircular e o pedúneulo muito curto.

\section{Medidas. -}

Comprimento da porẹão adnata das técas ...... 170-220 miera

Comprimento da porẹão livre das técas . . . . . 150-180 "

Diâmetro do orifício das técas ............ 90-100 " 
Diâmetro do caule ao nível das articulações ... 70-80 micra

Profundidade dos gonângios ............. 940-1400 "

Diâmetro máximo dos gonângios ............ 560-900 "

Procedência. - 20 milhas ao largo de S. João da Barra, a $22 \mathrm{~m}$. de profundidade, maio-julho de 1950.

Distribuição. - Cargados; Ilhas Gambier; Índias Neerlandêsas (Borneo, Sumbawa).

Discussão. - Billard (1925, p. 198) admite como duvidosa a separação específica desta forma, descrita por Jarvis (1921, p. 344) como espécie nova e atribuida ao gênero Pasythea. Billard (1. c.) justifica esta separação baseando-se na proporção diferente entre a parte livre e a parte adnata das técas. $D$. quadridentata é uma espécie euja morfologia é muito variável, devido em grande parte, ao fato de poder haver um maior ou menor número de pares tecais reunidos. Num mesmo cáule as proporȩões entre as várias partes das técas pode variar, como é fácil verificar pelas próprias figuras de Billard; considero, portanto, $o^{*}$ earáter apontado por êsse autor insuficiente para justificar a separação específica desta forma, Dynamena quadridentata $f$. heterodonta.

13. - Dynamena cornicina (Me Crady) 1858.

Dynamena cornicina Vannucei Mendes 1946, p. 562, t. 4, f. 33-34.

Procedência. - Ilha de S. Sebastião, canal, em mar raso.

14. - Sertularia marignata f. typica. (Kirch.) 1864.

Sertularia marginata Bedot 1925, p. 401.

" $\quad$ f. typica Vannucei 1949, p. 248.

Procedência. - Tha de S. Sebastião, canal, em mar raso. Encontrada em reprodução estolonífera, no mês de abril de 1949 .

15. - Sertularia marginata (Kirch. 1864) f. laxa Van. 1949.

Sertularia marginata f. laxa Vannueci 1949, p. 248, t. 3, f. 46.

Procedência. - Banco S. Tomé, entre 39 e $46 \mathrm{~m}$. de profundidade. Encontrada fértil, em maio-julho de 1950.

Distribuição. - Fértil em junho, perto da Marambáia, a $23^{\circ} 02^{\prime}$ lat. S. $-43^{\circ} 56^{\prime}$ long. W. 
16. - Sertularia perpusilla Stechow 1919.

t. 2, Fig. 13-14.

Sertularia perpusilla Stechow 1919, p. 89, M 1.

Tridentata perpusilla Stechow 1923, p. 204.

Sertularia perpusilla Broch, p. 80, f. 33.

Trofosoma. - Os poucos cáules que possúo desta espécie alcançam $5 \mathrm{~mm}$. de altura e apresentam 8 pares de técas contidos em $5 \mathrm{~mm}$. de eáule. Êste é simples, não ramificado, havendo um forte nó oblíquo abaixo do par basal. Os demais internódios são por vêzes muito mal delimitados, ou mesmo deixam de apresentar nós distintos. As técas do mesmo par são adnatas, o fundo tecal é horizontal, a margem é provida de dois largos dentes laterais e um ímpar mediano; não encontrei traços das valvas opereulares nos espécimes em mãos.

Gonosoma. - Existe um gonângio feminino inserido na base do primeiro par de técas. É grande, cilíndrico, com base cônica e um curto pedúnculo fortemente encurvado. O orifício é muito amplo e existem quatro profundas incisões anelares na gonotéca. Encontrada fértil em julho.

\section{Medidas. -}

Comprimento da porção adnata das técas .......... 150-235 micra Comprimento da porção livre das técas ........... 160-190 "

Distância entre os dentes medianos do mesmo par tecal .. 490-500 " Profundidade do gonângio .................... 1400 "

Diâmetro máximo do gonângio $\ldots \ldots \ldots \ldots \ldots \ldots \ldots . . \ldots 00$ "

Procedência. - 20 milhas ao largo de S. João da Barra a $22 \mathrm{~m}$. de profundidade. Julho de 1950.

Distribuição. - Mediterrâneo.

Discussão. - $O$ trofosoma desta espécie assemelha-se sobremaneira ao de S. gracilis. Não fôsse a diferente conformação dos gonângios, sem dúvida não poderiam ser separados especificamente. Falta averiguar se não se trata, também, neste caso, de um caráter sexual secundário; se assim fôsse, $S$. gracilis teria a prioridade. As gonotécas de S. gracilis são sub-ovais, com colarinho e sem reintrâncias anelares. A figura e as medidas apresentadas por Broch (1933, p. 80, f. 33) de S. perpusilla concordam perfeitamente tanto com o meu material de S. perpusilla como com o de Stechow e êste último nome deve ser mantido para o material mediterrâneo de Broch. Êsse autor (ł. c.), propõe interrogativamente a sinonímia de 
S. brevicyatus e $S$. perpusilla; não julgo possível aceitar essa sinonímia, pelos motivos seguintes: Versluys (1899, p. 40) sob o nome Desmoscyphus brevicyathus e Nutting (1904, p. 60) sob o nome genérico de Sertularia, descreveram e figuraram uma espécie com técas de conformação diferente das de Sertularia perpusilla, com a porção livre afunilada e fortemente entumescidas na sua parte basal. Nem Nutting, nem Versluys fornecem medidas, mas o último autor afirma que $S$. brevicyathus difere de $S$. gracilis, com a qual na realidade se parece, por possuir 7 pares tecais contidos em $5 \mathrm{~mm}$. de cáule, enquanto que, no mesmo intervalo, $S$. gracilis apresenta sòmente 6 . Stechow (1919, p. 92 , f. $\left.\mathrm{H}^{1}\right)$, apresenta as medidas de $S$. brevicyathus e também mantém as duas espécies separadas. Na espécie presente contam-se 8 pares tecais num intervalo de $5 \mathrm{~mm}$. Evidentemente S. gracilis, S. perpusilla e S. brevicyathus são espécies muito próximas mas não idênticas. De qualquer modo, pesquisas experimentais são, neste caso como em numerosos outros, altamente recomendáveis. O gênero Tridentata, instituido por Stechow (1923, p. 203), não pode ser aceito, pois os caractéres sôbre os quais se baseia êste autor são insuficientes para tanto; por êsse motivo, Tridentata perpusilla Stechow é sinônimo de S. perpusilla.

\section{Família Plumularidae.}

\section{7. - Plumularia lagenifera Allman 1885.}

\section{t. 3, Fig. 15-16.}

Plumularia lagenifera Nutting 1900, p. 65, t. 6, f. 6-10. non " " $\quad$ Torrey 1902, p. 77.

Plumularia setacea p. parte Bedot 1921, p. 29.

Trofosoma. - As colônias formam tufos densos, grandes, atingindo os cáules 7-8 $\mathrm{cm}$. de comprimento. Êstes são flexíveis, abundantemente ramificados, os hidrocládios são finos e moles. Os cáules são simples, não fasciculados, divididos em internódios bem marcados e regulares, todos hidrocladiados. As ramificações podem ser muito compridas e inserir-se nos cáules, no lugar de hidrocládios. Cada artículo caulinar tem um processo longo em sua extremidade distal, que ultrapassa o nível da articulação. Os artículos eaulinares têm 2 nematóforos sub-hidrocladiais e 1 ou 2 na axila de cada hidrocládio. $\mathrm{O}$ artículo basal de cada hidrocládio tem articulação basal reta e distal oblíqua, é curto, provido de um único espessamento perisareal, sendo desprovido de nematóforo. Os demais artículos hidrocladiais são alternadamente tecados e atecados. Tôdas as articulações são levemente oblíquas. Os artículos atecados têm espessamentos perisarcais situados perto das extremidades e um único nematóforo. Os artículos hidrotecados têm um espessamento perisarcal interno perto de cada nó e um incompleto abaixo da téca; as hidrotecas são mais largas 
do que profundas; ocorrem 3 nematóforos em cada artículo hidrocladiado, nm par supracalicino que se insere ao nível da margem tecal, e um mesial articulado na parte basal, alargada, do internódio.

Gonosoma. - As gonotécas inserem-se no processo distal do internódio caulinar, são ovais, alongadas, finas quando vistas de perfil e alargadas quando observadas da frente. Têm um pescoço longo e fino, com orifício circular estreito. Encontrada fértil em maio-julho de 1950.

\section{Medidas. -}

Comprimento dos internódios caulinares ........... 480-680 micra

Diâmetro do cáule ao nível das articulações .......... 150-160

Comprimento dos internódios hidrocladiais hidrotecados .. 320-400"

Comprimento dos internódios atecados hidrocladiais .... 160-180"

Profundidade das gonotécas .................. 800-1000 "

Diâmetro das gonotécas vistas de frente ........... 200-300 "

Diâmetro das gonotécas vistas de lado ............ 100-150 "

Procedência. - 20 milhas ao largo de S. João da Barra, a cêrca de $22 \mathrm{~m}$. de profundidade.

Distribuição. - Puget Sound, costas da Califórnia, Ilha Vancouver.

Discussão. - O material presente concorda inteiramente com a descrição de Nutting (1900, p. 65). Como já foi assinalado por êsse autor, à primeira vista, as colônias desta espécie parecem-se muito com as de $P$. setacea. Os traços típicos de $P$. lagenifera são os seguintes: encurvamento dos hidrocládios em direção do cáule; existência de dois nematóforos além dos axilares, em quase todos os internódios caulinares, dilatação da base dos segmentos hidrotecados hidrocladiais, achatamento das gonotécas. Além das demais particularidades, êsses caractéres distinguem fàcilmente $P$. lagenifera das demais espécies do gênero; discordo, dêste modo, de Bedot (1921, p. 29), que considera P. lagenifera sinônimo de P. setacea.

18. - Plumularia strobilophora Billard 1913.

t. 3, Fig. 17-18.

Plumularia strobilophora Billard 1913, p. 35, f. 26. " $\quad$ Bedot 1921, p. 29.

Trofosoma. - Os cáules desta espécie de Plumularia alcançam até $2,5-2,8 \mathrm{~cm}$. de altura e não são ramificados. O cáule é geniculado em sua parte distal mas não o é perto da base. Os internódios caulinares apre- 
sentam um forte processo lateral distal no qual é inserido o hidrocládio; o ápice dêsse processo não ultrapassa o nível do nó caulinar seguinte. Todos os internódios caulinares são hidrocladiados, na axila do processo há um ou dois nematóforos e outro, mais perto da base, em cada artículo caulinar. O artículo basal de cada hidrocládio é curto, enquanto a porção restante do cládio apresenta internódios tecados alternados com artículos atecados mais curtos. Os internódios tecados apresentam um nematóforo mesial e um par supracalicino, os internódios atecados têm um único nematóforo. As técas estão no meio do artículo, são cônicas e com orifício oblíquo em relação ao eixo do hidrocládio.

Gonosoma. - Os gonângios desta espécie são notáveis pelo seu tamanho reduzido e pela forma cônica, com amplo orifício escavado. Inserem-se na axila dos hidrocládios ou em seu lugar; encontrada fértil em maio-julho de 1950.

\section{Medidas. -}

Comprimento dos artículos caulinares ............ 415-480 micra

Diâmetro do eáule ao nível das articulações ......... 80-95 "

Comprimento dos internódios tecados hidrocladiais .... 480-560" "

Comprimento dos internódios atecados hidrocladiais .... 190-335 "

Profundidade das técas $\ldots \ldots \ldots \ldots \ldots \ldots \ldots \ldots \ldots \ldots$. $65-85$ "

Diâmetro do orifício das técas $\ldots \ldots \ldots \ldots \ldots \ldots \ldots \ldots$. 85-95 "

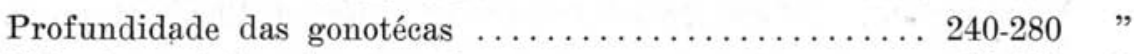

Diâmetro máximo das gonotécas ................. 95-110 "

Procedência. - Ilha da Trindade, entre 15 e $40 \mathrm{~m}$. de profundidade.

Distribuição. - Mares maláios, ilhas Kei.

Discussão. - Já Billard (l. c.) mostrou haver semelhanças entre $P$. strobilophora e $P$. megalocephala. É preciso acrescentar que, pelos caractéres do trofosoma esta espécie poderia também, à primeira vista, ser confundida com $P$. strictocarpa, o que não se dá, porém, pelo desenvolvimento propocional diferente das partes e, mais ainda, pelo tamanho e forma dos gonângios.

\section{9. - Schizotricha billardi (Billard) 1904, nom. nov.}

t. 3, Fig. 19-20.

non Plumularia alternata Billard 1913, p. 31. Plumularia alternata Billard 1904, p. 484, f. 4. Thecocaulus diaphanus Vannucei Mendes 1946, p. 576, t. 5, f. 46-47.

Schizotricha diaphana Vannucci 1949, p. 251.

" " Vannucei 1950, p. 89. 
Gonosoma. - Pela primeira vez encontrei colônias desta espécie ainda providas de gonotécas, se bem que já estivessem vazias em dezembro de 1950. Os gonângios inserem-se logo em baixo das técas caulinares. O pedúnculo, curto, cônico, é formado por duas anelações mał delimitadas, havendo, na distal, 2 nematóforos móveis. Os gonângios, pròpriamente, são piriformes, alongados, sendo o polo distal mais largo. O orifício é raso, sem colarinho.

Procedência. - Ilha de S. Sebastião, canal, em mar raso; dezembro de 1950.

Discussão. - Esta espécie já foi repetidamente descrita e foi até agora confundida com Schizotricha diaphana (Heller 1868), com a qual apresenta vários pontos de contato. Bedot (1914, p. 92), depois de mostrar que Plumularia alternata é sinônimo de $P$. diaphana (=Schizotricha diaphana), aponta que o material de Billard proveniente de Obock, muito provàvelmente pertence a uma espécie diferente. Anteriormente (Vannucei Mendes 1946, p. 577) assinalei a semelhança entre o material brasileiro e o da Somália Francêsa (Obock, mar Vermelho) e agora, ao encontrar o gonosoma, bastante diferente do de Schizotricha diaphana, não exito em identificar, especificamente, o meu material com o de Billard, e a considerar esta espécie diferente de $S$. diaphana, que é a espécie com a qual mais se parece. Os caractéres específicos de $S$. billardi são: gonotecas piriformes, enquanto as de $S$. diaphana têm forma de cornucopia, existência de 2 nematóforos nas gonotécas e não 4 como em S. diaphana, medidas levemente discordantes entre as duas espécies, dimorfismo das técas, o que nem sempre ocorre em S. diaphana, dimorfismo acentuado dos nematóforos de S. billardi (Vannucci 1949, p. 252) e, por fim, ausência de nematóforos nas hidrorrizas desta espécie.

20. - Monotheca margaretta f. typica Nutt. 1900.

Monoteca margaretta f. typica Vannueci Mendes 1946, p. 578, t. 5, f. 48; t. 6 , f. 54 .

Procedência. - Banco S. Tomé, entre 39 e $46 \mathrm{~m}$. de profundidade.

21. - Aglaophenia perforata Allman 1885.

t. 3, Fig. 21-23.

Aglaophenia perforata Nutting 1900, p. 99, t. 21, f. 14-15.

" $\quad$ Bedot 1918, p. 62.

" $\quad$ Bedot 1925, p. 83. 
Trofosoma. - As colônias presentes nessa coleção acham-se quebradas perto do ápice, mas assim mesmo, alcançam $2 \mathrm{~cm}$. de comprimento. O caule é simples, com 2 nós oblíquos perto da base. Os internódios caulinares são eurtos, exibem um processo mamilonar perfurado na base de cada hidrocládio e um par de nematóforos na axila do processo no qual se articula o hidrocládio. Os nós caulinares são mal separados uns dos outros. Os internódios hidrocladiais apresentam dois espessamentos perisarcais internos, um bem desenvolvido, em correspondência com o septo intratecal, e outro, mais tênue, em baixo dos nematóforos supracalicinos. As hidrotécas são amplas, com orifício largo. A margem é provida de 4 dentes de cada lado e um mediano, ímpar, bifurcado. O ramo dorsal do dente mediano pode se estender para trás ou se salientar para cima; o seu tamanho é variável. O septo intratecal é completo, formando ângulo reto com o hidrocládio; êle exibe um septo incompleto ou chanfradura ao nível em que se destaca da hidrotéca; sua cavidade está em comunicação com a câmara posterior da mesma.

Não encontrei córbulas.

\section{Medidas. -}

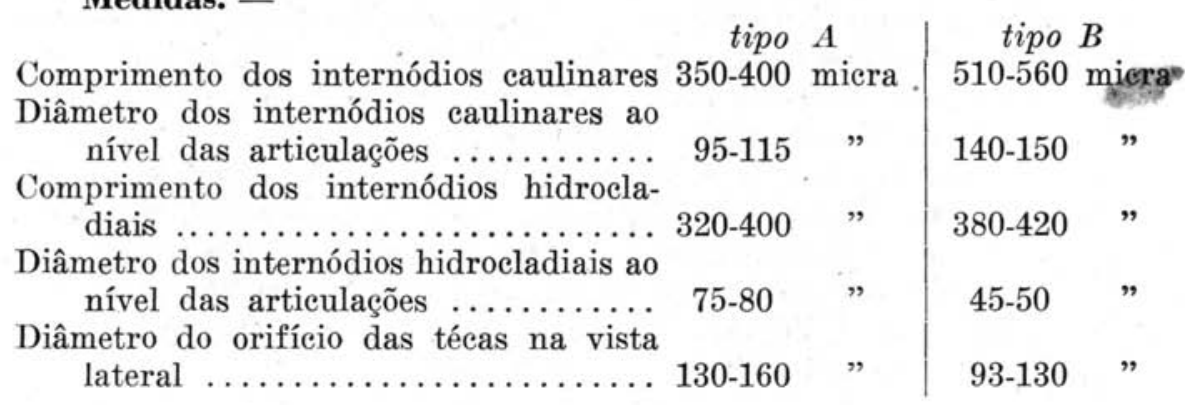

Procedência. - Ilha da Trindade, Banco S. Tomé.

Distribuição. - Ilha S. Vicente, mar dos Caraibas.

Discussão. - Difere o material presente do original de Allman (1. c.) e da descrição apresentada por Nutting (l. c.) pela existência de uma quilha tecal em certas hidrotécas de algumas das colônias. Como já demonstrei anteriormente (Vannucei Mendes 1946, p. 587), referindome a Aglaophenia late-carinata, êste caráter é variável e não tem valor decisivo para a diferenciação específica. Um dos cáules, cuja medição figura na tabela de medidas sob a indicação de tipo $\mathrm{B}$, tem internódios hidrocladiais e caulinares longos (o que determina maior distância entre os hidrocládios e uma menor densidade de hidrotécas), e tem hidrotécas mais profundas e com orifício menor. Todos os caractéres específicos concordam com a descrição acima e julgo que essas diferenças são apenas de caráter individual, não devendo ser considerada esta colônia nem mesmo como forma nova; as técas dêste cáule são desprovidas de. quilha, mesmo havendo bifureação do dente mediano ímpar. 
22. - Aglaophenia contorta Nutt. 1900.

Aglaophenia contorta Bedot 1925, p. 75 .

$" \quad " \quad$ Vennucei Mendes 1946, p. 583, t. 6, f. 56-59; 70.

Procedência. - Ilha de S. Sebastião, canal, em mar raso.

$$
\text { VI. - Cl. HYDROZOA. }
$$

Ord. TRACHYLINA. Sub-ord. TRACHYMEDUSAE Haeckel 1866 s. s.

Esta ordem é aqui considerada em sentido restrito, visto como foi removida para a ordem Leptolina a família Olindiidae (ver acima, p. 70).

As Trachymedusae são medusas craspedotas com litocistos inclusos na mesogléa, de origem endodérmica. A margem umbrelar é lisa, os tentáculos maciços, e as gônadas, habitualmente; desenvolvem-se nos. canais radiais; êsses são em número de 4-6 ou 8. O desenvolvimento é, pelo que se sabe, direto.

\section{Família Geryonidae Eschscholtz 1829.}

Trachymedusae com 4 ou 6 canais radiais nos quais se desenvolvem as gônadas achatadas, em forma de folha. Litocistos inclusos na mesogléa, localisados acima do canal circular. Estômago afunilado, pseudo-manúbrio presente. Pode haver divertículo do canal circular, centrípetos, em fundo cego. Ocorre no desenvolvimento uma actínula de vida livre que se transforma diretamente em medusa.

23. - Liriope tetraphylla (Cham. \& Eisen.) 1821.

t. 3, Fig. 24 .

Liriope rosacea Maas 1897 , v. 23, p. 26, t. 3, f. 7-8.

” compacta Maas 1905 , p. 62 , t. 9 , f. 55-59.

" rosacea Maas 1905, p. 63.

" tetraphylla Bigelow 1909, p. 112, t. 3, f. 6-7; t. 4, f. 2-3.

" rosacea Mayer 1910, p. 417, t. 52, f. 1.

" tethaphylla Thiel 1936, p. 45.

$" \quad$ " Carvalho 1943.

A maioria das medusas desta espécie que tenho em mãos, são incompletamente desenvolvidas, havendo machos e fêmeas de todos os tamanhos entre $3 \mathrm{~mm}$. e $11 \mathrm{~mm}$. de diâmetro, até $6 \mathrm{~mm}$. de altura. Notam-se nas 
gônadas de algumas fêmeas adultas, óvulos em crescimento já bastante desenvolvidos. A umbrela é hemisférica, com mesogléa mediocremente desenvolvida. O comprimento do pseudo-manúbrio + manúbrio é de $1,5 \mathrm{r}-2 \mathrm{r}$ ( $\mathrm{r}=$ ráio da umbrela ). As gônadas são triangulares, com os ângulos truncados e arredondados, quase cordiformes, quando bem desenvolvidas quase tocam o canal circular e ocupam $2 / 3$ a $3 / 4$ do comprimento do canal radial. Ã medida que as gônadas crescem, tendem a adquirir uma forma arredondada, distando uma da outra $1 / 2 \mathrm{~b}$ ou menos ( $\mathrm{b}=$ diâmetro máximo das gônadas). O canal circular é nítido, os divertículos centrípetos em fundo cego são, nas medusas de 10-11 mm. de diâmetro, em número de 3 em cada quadrante. Um mediano, interradial, cônico, que se prolonga até $1 / 3$ da ex-umbrela, é ladeado por dois divertículos curtos, também cônicos. No adulto não permanecem vestígios dos 4 tentáculos radiais maciços, êsses são inteiramente substituidos por tentáculos longos de cêrea de $4 \mathrm{r}$ quando distendidos. Existem 4 tentáculos interradiais curtos. Ocorrem 8 litocistos.

Procedência. - Região de Cananéia (mar do Cubatão), em 30 10-49; também defronte da Ponta do Arrozal, em 6-8-49. 1 exemplar maduro em 21-7-51, de $20 \mathrm{~mm}$. de diâmetro (animal vivo), no Mar Pequeno a $200 \mathrm{~m}$. da Barra. Na Ponte do Arrozal, foram encontradas juntamente com numerosas medusas imaturas, muito pequenas; provàvelmente pertencentes ao gênero Olindias. Em 24-6-49 foi encontrada na região de Cananéia, estação $I_{v}$ entre a Ponta do Cambriú e a Ilha homônima, uma grande quantidade de medusas jovens, em todos os estados de desenvolvimento, desde a fase de 4 tentáculos e início do brotamento do pseudomanúbrio, até a fase de primórdio das gônadas, pertencentes ao gênero Liriope. Condições ambientes: 12 h., maré montante, vento NW forte, temperatura da água $21^{\circ}, 7 \mathrm{C}$.

Distribuição. - Se a sinonímia $L$. rosacea $=L$. tetraphylla fôr aceita, evidentemente, a espécie será vastamente distribuida. Se $L$. rosacea fôr considerada espécie à parte, então, sua distribuição será a seguinte: Florida, Tortugas, até a região equatorial atlântica nas costas do Brasil.

Discussão. - Segundo Mayer (1. c.), foram descritas sob nomes específicos diferentes: $L$. crucifera, $L$. compacta e $L$. rosacea, medusas pertencentes tôdas à mesma espécie, mas em diferentes fases de desenvolvimento. Possìvelmente tôdas essas espécies seriam sinônimas de L. tetraphylla. A julgar pelas descrições e figuras respectivas, é bem provável que a opinião de Mayer seja correta e eu a sigo sem restrições; de qualquer modo, o material presente concorda inteiramente com a espécie descrita e figurada por Mayer sob o nome de L. rosacea (1910, t. 52, f. 1), proveniente das Ilhas Tortugas, no mar dos Caraibas. A classificação específica das espécies do gênero Liriope é extremamente difícil, devido à pequena diferença entre as espécies, à grande variabilidade intraespecífica, e, finalmente, à vasta distribuição do gênero. Estudos mais profundos sôbre 
a morfologia e a área de distribuição de cada suposta espécie, assim como contagens em larga escala, poderiam oferecer resultados muito interessantes. Carvalho (1943), encontrou no plancton da região de Santos medusas do gênero Liriope, que classificou como L. tetraphilla, aceitando a opinião recente de Thiel $(1936$, p. 45), já aventada por Browne $(1927$, p. 109) e Bigelow (1918, p. 389), segundo a qual tôdas as espécies do gênero poderiam ser enquadradas numa única espécie, extremamente variável. O material de Carvalho (l. c.) é muito provàvelmente idêntico ao atual, dependendo sua denominação de se aceitar ou não a sinonímia com $L$. tetraphylla. Mayer (l. c.) aponta a possível sinonímia com L. tetraphylla, tendo êsse último nome a prioridade, pois, encontrou nas Ilhas Tortugas espécimes morfològicamente intermediários entre as duas espécies. Creio que, de fato, foi multiplicado, desnecessàriamente, o número de espécies no gênero Liriope, mas parece difícil acreditar que L. scutigera, L. minima e $L$. hiperbolica, por exemplo, pertençam à mesma espécie, pois nelas difere o desenvolvimento e a forma das gônadas, o comprimento proporcional do manúbrio, a forma da umbrela etc. e, não obstante, encontram-se as três no Oceano Atlântico.

As Geryonidae são consideradas medusas tìpicamente do alto mar, adaptadas de tal modo à vida pelágica que até se perdeu, no seu ciclo evolutivo individual, a fase polipóide fixa, dando-se o seu desenvolvimento diretamente através de uma larva planctônica livre, a actínula, a qual se metamorfoseia diretamente em medusa. Entretanto, os espécimes presentes provêm de mares internos, com ampla comunicação com o mar aberto, é verdade, mas por outro lado também fortemente expostos à influência das marés. Foram recolhidos na maré enchente, no máximo a $3-4 \mathrm{Km}$. da barra. As medusas provenientes da Ponta do Arrozal estavam acompanhadas de grande quantidade de Diatomáceas, Coscinodiscus sp. Outros organismos planctônicos tìpicamente marinhos já foram, repetidas vêzes, encontrados no mesmo ponto da região lagunar de Cananéia, ou em pontos comparáveis, como por exemplo as diatomáceas Endyctia oceanica, espécies do gênero Surirella e espécies do gêneró Ceratium, pertencente às Dynophyceae (Carvalho 1950, p. 32, 39, 40). As Trachymedusae acham-se, sob certos pontos de vista, situadas não muito distantes, das Limnomedusae, que se encontram habitualmente em águas costeiras, salôbras ou dôces.

\section{VII. - Cl. SCYPHOZOA.}

\section{Ord. RHIZOSTOMEAE}

Scyphomedusae desprovidas de tentáculos marginais verdadeiros, com o manúbrio subdividido em oito braços bucais franjados. A bôca primitiva está ocluida, sendo substituida por numerosas bôcas minúsculas localizadas nas ramificações dos braços bucais. As bôcas secundárias são ladeadas por pequenos tentáculos que estão em movimento contínuo. 
Rhizostomata triptera Vanhöffen, sens. Maas 1903.

Rhizostomeae com braços bucais, euja porção inferior está subdividida longitudinalmente em 3 partes, de tal modo que o corte transversal tem forma de Y. As bôcas estão localizadas ao longo das margens dessas três saliências.

24. - Lychnorhiza lucerna Haeckel 1880.

t. 4, Fig. 25-27.

Lychnorhiza lucerna Mayer 1910, p. 673.

" flagellata Haeckel, seg. Mayer 1910, p. 673.

Tenho em mãos 24 exemplares dessa espécie, cujo diâmetro umbrelar varia de 2 a $15 \mathrm{~cm}$. depois de fixados. A exumbrela é coberta de minúsculas nodosidades que se prolongam até sôbre as franjas marginais e, em alguns indivíduos, ocorrem protuberâncias eônicas. Existem 8 ropálios dispostos nos radii e interradii. Os ropálios são ladeados por 2 franjas delgadas; além dessas existem 4 franjas largas, em cada octante; estas franjas marginais com formato triangular são bem maiores que as franjas ocelares e com o ápice mais obtuso. Os 8 braços bucais, adradiais, são comprimidos lateralmente, separados uns dos outros a partir do diseo gástrico e são pouco mais curtos que o diâmetro umbrelar. Cada braço bucal possue saliências ou "asas" longitudinais, uma mediana interna provida de numerosas dobras e bôcas; e duas externas, mais desenvolvidas do que a mediana e com maior número de dobras e de bôcas. Ladeando as bôcas existem inúmeros tentáculos claviformes, que, no material conservado em formol a 4\%, não ultrapassam 400-450 micra de comprimento. Existem também apêndices filiformes que podem alcançar alguns centímetros de comprimento, todavia, não os encontrei nem tão numerosos nem tão longos como os menciona Mayer (l. e.). A musculatura circular sub-umbrelar é bem desenvolvida e não apresenta interrupȩões. $O$ estômago cruciforme é muito amplo ; os braços da cruz terminam abruptamente e têm $1 / 2 \mathrm{r}(\mathrm{r}=$ ráio da umbrela $)$ de comprimento e $1 / 3 \mathrm{r}$ de largura. Existem 4 canais radiais em cada quadrante: 1 radial, 1 interradial e 2 perradiais, saindo lateralmente do ápice dos braços da eruz. 0 eanal circular está aproximadamente a meio caminho entre o ápice dos braços da cruz e a margem umbrelar (não incluindo na medição o comprimento das franjas marginais). Do canal circular derivam 32 canais centrípetos, curtos, largos, irregulares. Externamente ao canal circular há uma rêde de canais anastomosados, que se extende até as franjas marginais, dentro da qual, porém, é possível reconhecer a continuação, em direção à margem, dos 4 canais radiais e dos 4 canais interradiais. As gônadas são extensas e salientes na cavidade sub-genital quando bem desenvolvidas. A cavidade sub-genital é única e ampla, sendo o diâmetro dos 4 óstios genitais cêrea de 3 vêzes maior do que a espessura dos pilares entre êles. 
Procedência. - Região de Cananéia, tôda a região barra a dentro, em 6-8-1949 e 26-5-1951.

Distribuição. - Rio de Janeiro, Pernambuco.

Discussão. - Admito decididamente a sinonímia proposta por Mayer, que considera $L$. flagellata apenas como uma fase jovem de $L$. lucerna Haeckel. De fato, não encontrei nenhum caráter distintivo digno de nota nas duas descrições e os exemplares imaturos da presente coleção, permitem resolver a questão. $O$ achado presente vem dilatar para o sul a área conhecida de distribuição desta espécie.

Dos 24 indivíduos estudados, 18 apresentavam larvas jovens de Cestodes, provàvelmente Tetrarhynchidea, na mesogléa, mormente na umbrela (Vannueci Mendes 1944, p. 48). Não encontrei nenhuma fase encistada, de modo que não me é possível classificar os parasitas; algumas das medusas não apresentavam mais do que 2 ou 3 vermes. As 6 medusas desprovidas de parasitas eram também as menores do lote, e êsse fato, assim como o de aleançar a $75 \%$ o número de indivíduos parasitados, indicam mais uma vez não ser um mero acaso a presença de larvas de Tetrarhynchidea dentro da mesogléa de medusas.

\section{VIII. - SUMMARY.}

Continuing the inventory of the Coelenterate Fauna of the brazilian coast, 23 species of Hydrozoa and a Scyphomedusa are recorded from different points of the coast aproximately between $22^{\circ}$ and $24^{\circ}$ lat. S.

Of these, 14 species were already known from other points of the coast and the remaining 10 were unknown from this latitude. Two species are here listed as new, they are: Halocordyle fragilis and Calicella gabriellae.

1. - Halocordyle fragilis, Stechow's (1923) correction of the generic name Pennaria has been followed, shows remarkable distinctive specific characters such as: alternate distribution of the cladii which do not lie all in the same plane, they are inserted at random on the hydrocaulus with a tendency towards a spiral dexiotropic distribution, sparse distribution of the pedicels which are alternate and not all located on the same side of the hydrocladium, and, finally, the long, wiry aspect of the colony which is as brittle as light glass. This eharacteristies are not sufficient, to my belief, to establish a new genus, since the polyps and the gonophores are entirely of the Halocordyle type, but they confer upon the species a very peculiar habitus.

2. - Calicella gabriellae forms erect hydrocauli which are extremely soft and flexuose, with hydrothecate and intermediate internodes. The thecae are deep, eylindrical, with a conical base, there are 10-12 long and narrow opereular valves. The gonangia are small, conical, with a short distal digitiform process. The included sporosac exhibits maturing ova. 
Dynamena heterodonta described by Jarvis (1922) as a new species, is here considered as a new form of the very variable species Dynamena quadridentata.

Schizotricha billardi nom. nov., is specifically separated from Sch. diaphana (Heller) to which it had been identified up to know. The brazilian colonies agree with the French Somaliland specimens deseribed by Billard (1904) and they are reunited in a new species named after the French worker. The main difference between the two mentioned species are: shape and size of the gonothecae, of the thecae and of the nematophores.

A description is given of all the species not previously recorded from the brazilian coast as well as biological observations on Olindias sambaquiensis whose shoals during winter months are very large and may entangle partially the fishermen's nets. Its feeding and swimming habits are described and the species proves to be an excellent laboratory animal both for class and research purposes, for it easily endures long transportation (even up to 12 hours during summer months) as well as unoxygenized acquaria and nevertheless greadily feeds on any animal food.

\section{IX. - BIBLIOGRAFIA.}

Allman, G. J. $1864, \ldots \ldots$ On the Construction and Limitation of Genera among the Hydroida. Ann. Mag. Nat. Hist. ser. 3, v. 13, p. 345-380. London.

Bédot, M. 1918, ......... Matériaux pour servir à l'Histoire des Hydroïdes. $6^{\text {ème }}$ période (1891-1900). Rev. Suisse Zool. v. 26, suppl. p. 1-376, Genève.

$" \quad " 1921, \ldots \ldots \ldots \ldots$ Notes systématiques sur les Plumularides. $2^{\text {ème }}$ partie. Rev. Suisse Zool. v. 29, n. 1, p. 1-40, Genève.

$" \quad " \quad 1925, \ldots \ldots \ldots \ldots$ Matériaux pour servir à l'Histoire des Hydroïdes. $7^{\text {ème }}$ période (1901-1910). Rev. Suisse Zool. v. 32, p. 1-657. Genève.

Bigelow, H. B. 1909, ...... The Medusae. Rep. Scient. Res. Voy. "Albatross". Mem. Mus. Comp. Zool. Harvard. v. 37, 243 p. 48 t. Cambridge, Mass.

$" \quad " \quad " 1918, \ldots \ldots$. Some Medusae and Siphonophorae from the Western Atlantic. Bull. Mus. Comp. Zool. v. 62 , n. 8 , p. $365-442,8$ t. Cambridge, Mass.

Billard, A. 1904, ......... Hydroïdes récoltés par M. Ch. Gravier dans le Golfe de Tadjourah. Bull. Mus. Hist. Nat. Paris. v. 2, p. $480-485$, Paris. 
Billard, A. 1905, ......... HydroÏdes récoltés par M. Seurat aux îles Gambier. Bull. Mus. Hist. Nat. Paris. v. 11, p. 331-335. Paris.

$" \quad " 1906, \ldots \ldots \ldots$. Hydrö̈des. Exp. Scient. "Travailleur" et "Talisman". v. 8, p. 153-243. Paris.

" $\quad " 1913, \ldots \ldots \ldots$. Les Hydrö̈des de L’Expédition du "Siboga". I. - Plumulariidae. p. 1-115, t. 1-16. Leide.

" $\quad " \quad 1925, \ldots \ldots \ldots$ Les Hydrö̈des de L'Expédition du "Siboga". II. - Synthecidae et Sertularidae. p. 117232 , t. 7-9. Leide.

Broch, H. 1933, ........ Zur Kenntnis der Adriatischen Hydroidenfauna von Split. Norske Videnkasp-Akad. Oslo. I Mat. Naturw. Kl. 1933, n. 4, p. 1-115. (paginação da separata). Oslo.

Browne, E. T. 1926, ..... Report on the Medusae. Cambridge Exp. Suez Canal Trans. Zool. Soc. London, v. 22, p. 105-115. London.

Carvalho, J. de P. 1943, ... Ucorrência do gênero Liriope no plancton de Santos e S. Vicente. Bol. Ind. Anim. n. 148 , p. $105-111$, t. 1 . S. Paulo.

Cunha, A. X. da, 1940, ... Contribuição para o estudo de hidropolipos das costas de Portugal. Arq. Mus. Bocage. n. 11, p. 105-120. Lisboa.

" " " " 1944, ... Hidropolipos das costas de Portugal. Mem. Mus. Comp. Zool. Univ. Coimbra. n. 161, p. 1-101. Coimbra.

Fraser, C. McLean, 1912,.. Some Hydroids of Beaufort, North Carolina. Bull. Bur. Fish. v. 30, p. 339-387.

Issel, R. 1912, . . . . . . . Biologia neritica mediterranea. Il bentos delle foglie della Posidonia studiato dal punto di vista bionomico. Zool. Jahrb. Syst. v. 33 , p. $379-420$, t. 11-12. Jena.

Jarvis, F. E. 1921, ....... The Hydroids from the Chagos, Seychelles and other Islands and from the coast of British East Africa and Zanzibar. Trans. Linn. Soc. London, v. 7, p. 331-360, t. 24-26. London.

Kramp, P. L. 1938, ...... Die Medusa von Ostroumovia inkermanica (Pa. - Ostr.) und die systematische Stellung der Olindiiden. Zool. Anz. v. 122, p. 103-108. Leipzig. 
Kramp, P. L. 1939, ...... Freshwater Medusae in China. Proc. Zool. Soc. London, v. 120, part 1, p. 165-184. London.

Maas, O. 1905 a $\ldots \ldots \ldots$. Die Craspedoten Medusen der Siboga-Expedition. Siboga-Exp. n. 10, p. 1-84, t. 1-14. Leiden.

" 1905 b, ....... Die Medusen - Rep. Scient. Res. Voy. "Albatross". Mem. Mus. Comp. Zool. v. 26, p. 326 .

Mayer, A. G. 1910, ...... Medusae of the World. 3v. XV+XV+IV+ +735 p., 76t. Carnegie Inst. Washington.

Müller, F. 1861, ........ Polypen und Quallen von Santa Catharina. Olindias sambaquiensis n. sp. Arch. Naturg. ano 27 , v. 1 , p. $312-319$, t. 9 . Berlin.

Nutting, C. C. $1900, \ldots \ldots$. American Hydroids. Part I. - The Plumularidae. Spec. Bull. Smiths. Inst. U. S. Nat. Mus. 285p. 34t. Washington.

$" \quad$ " $\quad 1904, \ldots \ldots$. American Hydroids. Part II. - The Sertularidae. Spec. Bull. Smith. Inst. U. S. Nat. Mus. 325 p. 41 t. Washington.

$" \quad " \quad " 1915, \ldots \ldots$. American Hydroids. Part III. - The Campanularidae and the Bonneviellidae. Spec. Bull. Smith. Inst. U. S. Nat. Mus. 126 p. 27 t. Washington.

Stechow, E. 1919, ....... Zur Kenntnis der Hydroidenfauna des Mittelmeeres, Amerikas und anderer Gebiete, etc. Zool. Jahrb. Syst. v. 42, p. 1-172. Jena.

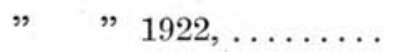

Zur Systematik der Hydrozoen, Stromatoporen, Siphonophoren, Anthozoen und Ctenophoren. Arch. Naturg. v. 88A, n. 3, p. 141-155. Berlin.

$" \quad " 1923, \ldots \ldots \ldots$ Zur Kenntnis der Hydroidenfauna des Mittelmeeres, Amerikas und anderer Gebiete. II Teil. Zool. Jahrb. Syst. v. 47, p. 29-270. Jena.

Thiel, M. E. 1936, ....... Systematische Studien zu den Trachylinae der Meteor Expedition, zugleich ein Beitrag zu einer Revision der Trachilinae. Zool. Jahrb. Syst. v. 69, p. 1-92. Jena.

Torrey, H. B. 1902, ...... The Hydroida of the Pacific coast of North America. Univ. Calif. Publ. Zool. v. 1, p. 1-104, t. 1-11. Berkeley. 
Vannucci Mendes, M. 1944, . Sôbre a larva de Dibothriorhynchus dinoi, sp. n. parasita dos Rhizostomata (Cest. Tetrarhynchidea). Arq. Mus. Paranaense. v. 4, p. 47-82, t. 3-5. Curitiba.

" " "1946, . Hydroida Thecaphora do Brasil. Arq. Zool. Est. S. Paulo, v. 4, p. 535-598, t. 1-7. S. Paulo.

$" \quad " \quad " 1948$, . On Vallentinia gabriellae n. sp. (Limnomedusae). Bol. Fac. Fil. Ciêne. Letr. Univ. S. Paulo, Zool. n. 13, p. 73-91. S. Paulo.

Vannucei, M. 1949, ........ Hydrozoa do Brasil. Bol. Fac. Fil. Ciênc. Letr. Univ. S. Paulo, Zool. n. 14, p. 219-266, t. 1-3. S. Paulo.

$" \quad " 1950, \ldots \ldots .$. Resultados científicos do eruzeiro do "Baependi" e do "Vega" à Ilha da Trindade. Hydrozoa. Bol. Inst. Paul. Ocean. v. 1, n. 1, p. $81-96$, t. 1-2. S. Paulo.

$" \quad " 1951, \ldots \ldots \ldots$ Distribuição dos Hydrozoa até agora conhecidos nas eostas do Brasil. I. Bol. Inst. Paul. Ocean. v. 2, n. 1, p. 105-124. S. Paulo.

Versluys, J. 1899, ........ Hydraires Calyptoblastiques recueillis dans la Mer des Antilles. Mém. Soc. Zool. France. v. 12 , p. 29-58. Paris.

\section{X. - ESTAMPAS.}

\section{Estampa 1.}

Fig. 1 - Olindias sambaquiensis, indivíduo com gônadas ainda pequenas : a - tentáculo primário; b - tentáculo secundário; c - o mesmo, contraído em espiral; d — protuberância claviforme.

Fig. $2-$ Halocordyle fragilis, fragmento de hidrocládio.

Fig. 3 - Halocordyle fragilis, hidrante.

Estampa 2.

Fig. 4-Olindias sambaquiensis, jovem.

Fig. 5 - Calicella gabriellae, fragmento do cáule e hidroteca.

Fig. 6 - Calicella gabriellae, gonângio. 
Fig. 7 - Calicella gabriellae, hidroteca e detalhe da margem e das valvas opereulares.

Fig. 8-Obelia commissuralis, fragmentos do cáule com medusas jovens saindo do gonângio.

Fig. 9 - Obelia commissuralis, gonângio.

Fig. 10 - Thaumantias raridentata, téca.

Fig. 11 - Dynamena quadridentata f. heterodonta, fragmento do cáule.

Fig. 12 - Dynamena quadridentata f. heterodonta, gonângio.

Fig. 13 - Sertularia perpusilla, fragmento do cáule com gonângio.

Fig. 14 - Sertularia perpusilla, téca.

Estampa 3.

Fig. 15 - Plumularia lagenifera, trofosoma.

Fig. 16 - Plumularia lagenifera, o mesmo gonângio, visto de frente e de lado.

Fig. 17 - Plumularia strobilophora, trofosoma.

Fig. 18 - Plumularia strobilophora, dois gonâncios do mesmo cáule.

Fig. 19 - Schizotricha billardi, fragmento do cáule com um gonângio.

Fig. 20 - Schizotricha billardi, gonângio.

Fig. 21 - Aglaophenia perforata, téeas, vista lateral.

Fig. 22 - Aglaophenia perforata, téca, vista de frente.

Fig. 23 - Aglaophenia perforata, nematóforo supracalicino.

Fig. 24 - Liriope tetraphylla.

\section{Estampa 4.}

Fig. 25 - Lychnorhiza lucerna, vista do polo oral, parte dos braços bucais removidos.

Fig. 26 - Lychnorhiza lucerna, vista do polo aboral.

Fig. 27 - Lychnorhiza lucerna, ropálio. 
VAsveci, M. Hydrozoa e Scyphozoa existentes no Instituto Paulista de Oceanografia.

ESTAMPA 1
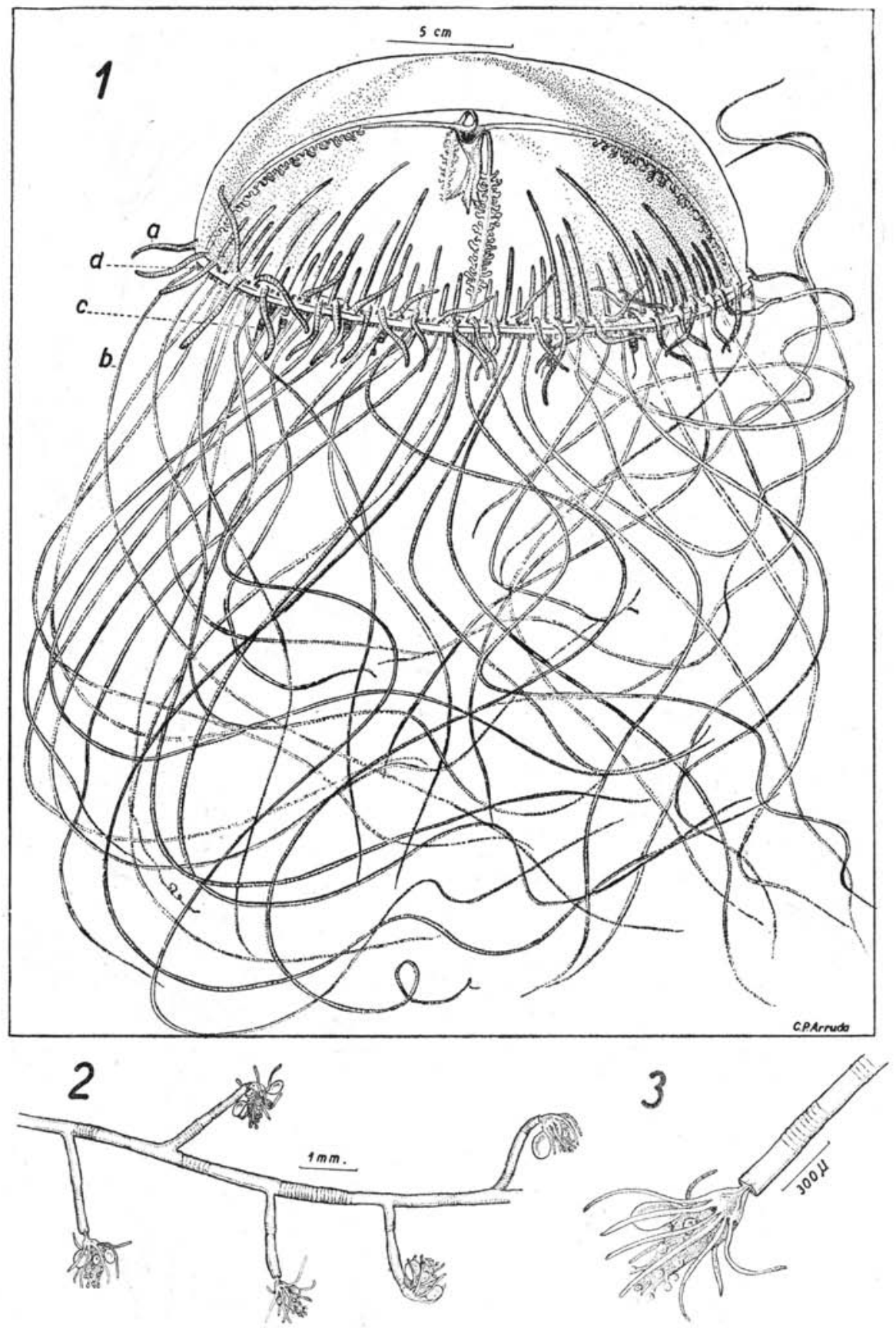


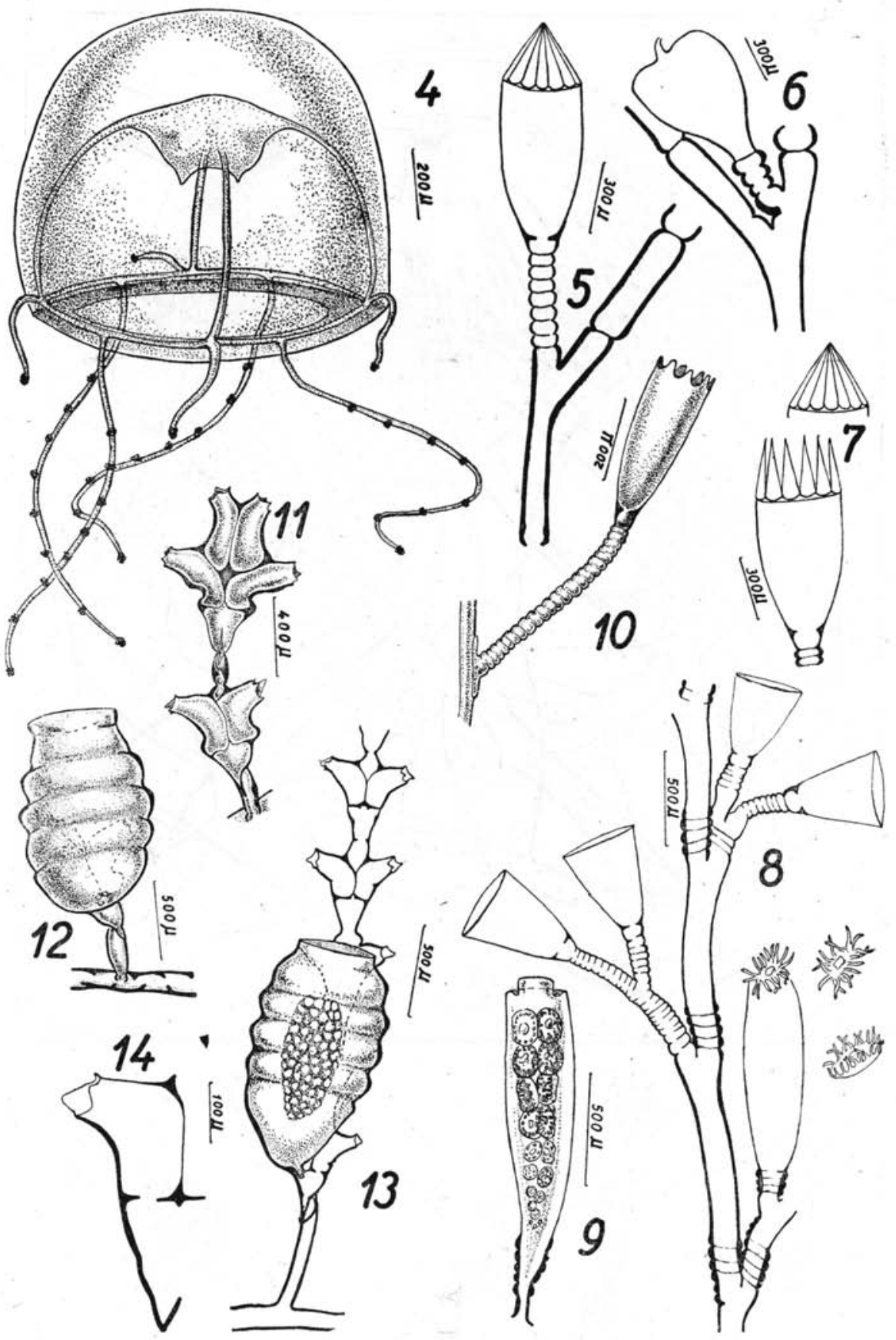


ESTAMPA 3

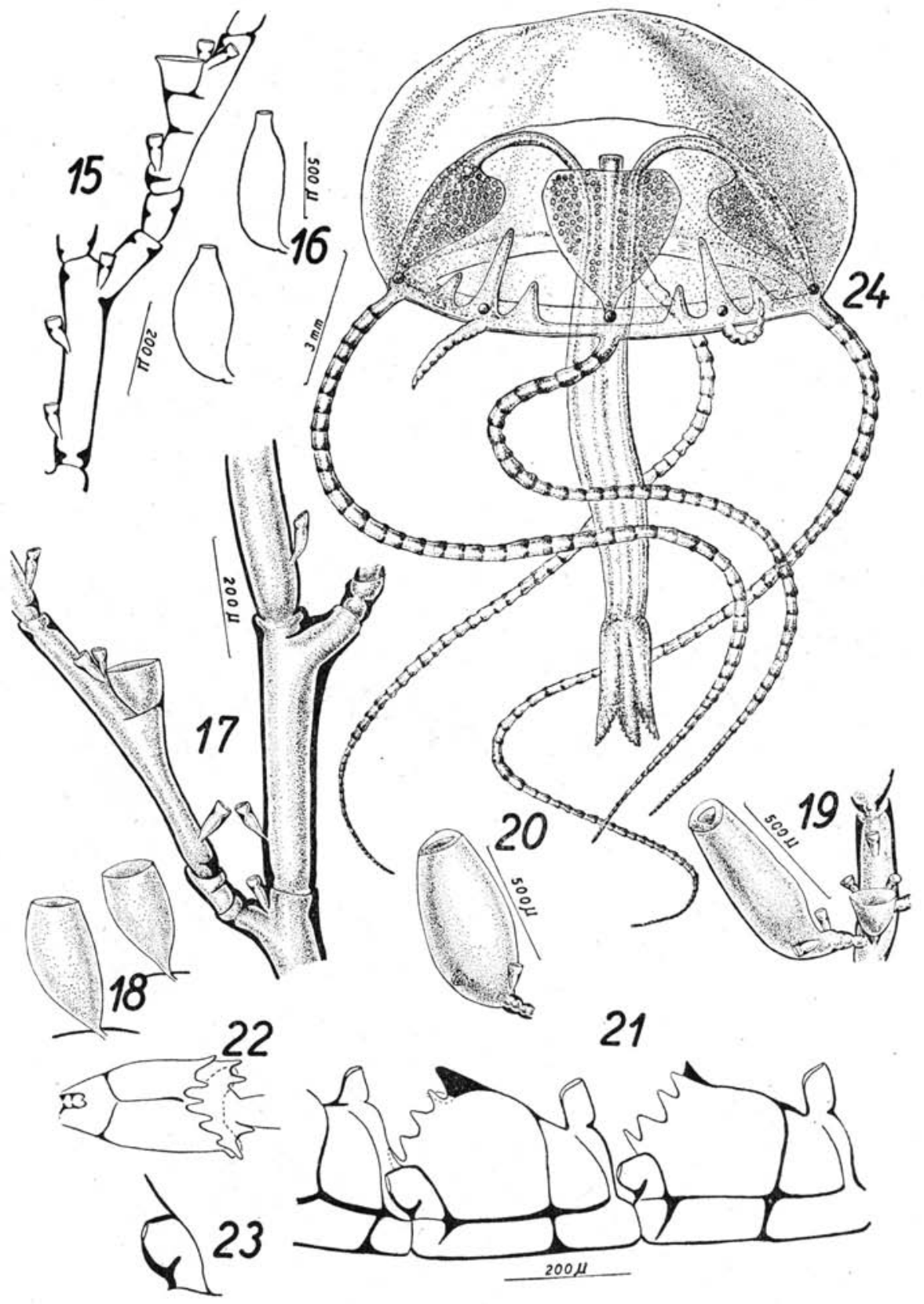




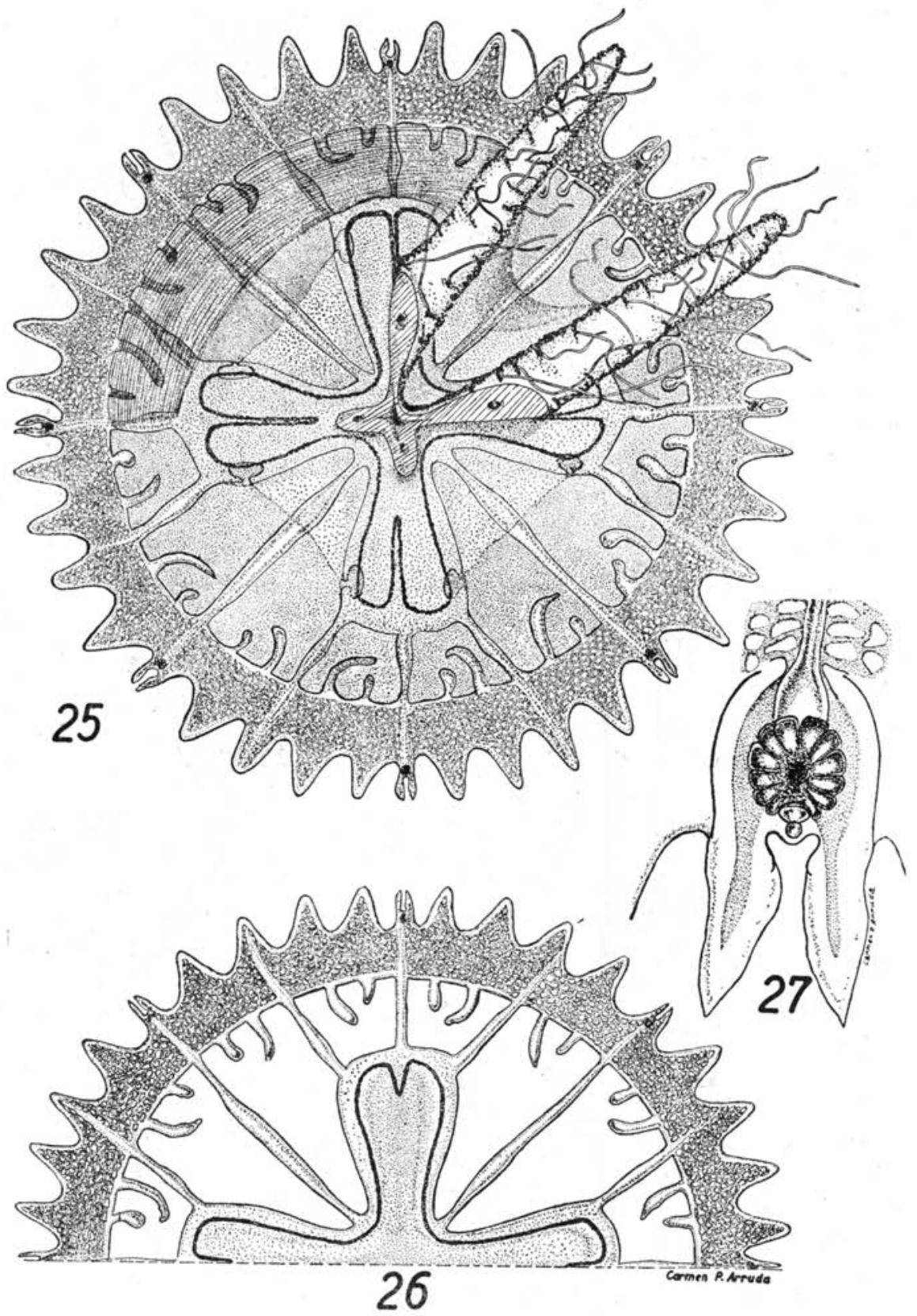

